\title{
Comunicação
}

[Communication]

\section{Parasitóides de dípteros coletados em fezes de búfalos em uma propriedade rural em Itumbiara, Goiás}

\author{
[Parasitoids of dipterous collected in buffalo dung in a rural property in Itumbiara, Goias, Brazil]

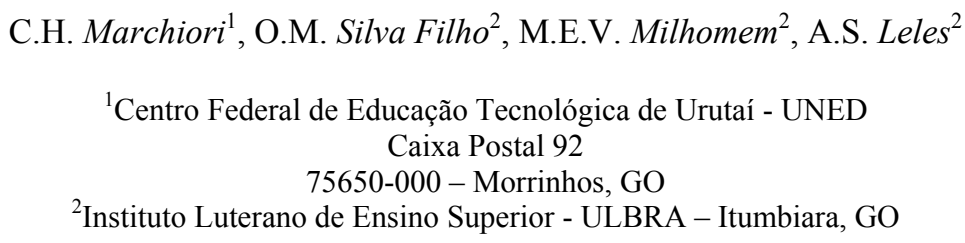

Alguns dípteros são de fundamental importância médica e veterinária, uma vez que podem produzir mí́ases (Oliveira et al., 2004) e atuar na veiculação de patógenos aos seres humanos e outros animais (Greenberg, 1971). Os dípteros são potenciais vetores mecânicos de agentes etiológicos como: vírus, bactérias, cistos de protozoários e ovos de helmintos (Greenberg, 1971). A ocorrência, distribuição e predominância de dípteros nas áreas metropolitanas são fatores de grande importância em Saúde Pública. Na zona rural, podem acarretar diminuição da produção de ovos, doenças nos animais, além de causar incômodo à população vizinha às criações (Berti Filho et al., 1996).

Além dos inseticidas, também podem ser usados como controle dos insetos os chamados reguladores naturais tanto na agricultura como em áreas de criação animal. O controle químico de insetos em ambiente urbano e rural é dificultado devido ao perigo de contaminação de seres humanos, de animais e do meio ambiente. Portanto, o controle biológico de moscas com uso de parasitóides vem ao encontro da busca de alternativas para o problema, por ser um método seguro, de fácil manuseio e baixo custo (Silveira et al., 1989; Carvalho et al., 2003). Alguns autores acreditam ser necessário pesquisar novas metodologias que visem ao controle das moscas (Mendes e Linhares, 1993).

O objetivo deste estudo foi verificar as espécies de parasitóides associados a Diptera em fezes de búfalos coletados no município de Itumbiara, Sul de Goiás, Brasil.
O experimento foi realizado na Fazenda do Curso de Agronomia do ILES-ULBRA, situada próximo às margens do Rio Paranaíba a $23 \mathrm{~km}$ de Itumbiara, GO (18 $25^{\prime} \mathrm{S}$ e $\left.49^{\circ} 13^{\prime} \mathrm{W}\right)$. Quinzenalmente, 10 placas de fezes frescas de búfalos foram marcadas nas pastagens, com auxílio de estacas de madeira branca $(30 \mathrm{~cm}$ de altura e $5 \mathrm{~cm}$ de espessura), para a determinação precisa de sua localização e tempo de exposição no campo, onde permaneceram por 10 dias. Posteriormente, oito amostras foram coletadas e levadas para o laboratório, para a extração das pupas pelo método da flotação usando-se $5 \mathrm{~cm}$ do substrato. As pupas foram retiradas com o auxílio de uma peneira, contadas e individualizadas em cápsulas de gelatina (número 00) até a emergência dos dípteros e/ou dos parasitóides. Os parasitóides e as moscas emergidos foram identificados morfologicamente com auxílio de um microscópio estereoscópio e, posteriormente, conservados em álcool $70 \%$

A porcentagem total de parasitismo foi calculada mediante contagem do número de pupas parasitadas/número total de pupas coletadas x 100 . A porcentagem de parasitismo de cada espécie de parasitóide foi calculada mediante contagem do número de pupas parasitadas por cada espécie de parasitóide/número total de pupas daquele hospedeiro x 100 .

A identificação dos parasitóides adultos foi realizada com a utilização de chaves de Legner et al. (1976), Rueda e Axtell (1985) e Díaz et al. (2000) e a dos hospedeiros adultos, de McAlpine et al. (1981), Amaral (1996) e Carvalho e Pont (1997).

Recebido em 8 de novembro de 2006

Aceito em 25 de setembro de 2007

E-mail: chmarchiori@yahoo.com.br 


\section{Marchiori et al.}

A preferência dos parasitóides pelos seus hospedeiros foi testada pelo qui-quadrado, com $5,0 \%$ de probabilidade.

Coletaram-se, no período de maio de 2003 a junho de 2004, 3473 pupários de dípteros, dos quais 172 pupas apresentaram-se parasitadas por parasitóides, pertencentes a três famílias e 10 espécies (Tab. 1). A porcentagem de parasitismo foi de $5,0 \%$ $(172 / 3473)$.

Spalangia drosophilae Ashmead (Hymenoptera: Pteromalidae) foi a espécie mais coletada com 21,5\% (37/172) , seguida de Paraganaspis egeria Díaz e Gallardo (Hymenoptera: Figitidae) com $16,3 \%$ (28/172). S. drosophilae é citada na literatura como parasitóide de pupas de dípteros pequenos das famílias Chloropidae, Drosophilidae, Muscidae, Sarcophagidae e Sepsidae (Marchiori et al., 2001; Marchiori, 2002; Marchiori et al., 2002b). O fato de se utilizar de muitos dípteros, $S$. drosophilae favorece sua permanência no meio ambiente, aumentando o seu potencial como agente no controle biológico de espécies-pragas.

Em fezes bovinas coletadas em Itumbiara-GO, $P$. egeria também foi a espécie mais freqüente com 60,6\% (Marchiori e Linhares, 1999). Foi encontrada parasitando Chrysomya albiceps
(Wiedemann) (Diptera: Calliphoridae) em carcaça de suíno, Palaeosepsis spp. (Diptera: Sepsidae) e Sarcophagula occidua (Fabricius) (Diptera: Sarcophagidae) em fezes bovinas e Fannia pusio (Wiedemann) (Diptera: Fanniidae) em fezes humanas, fígado bovino e vísceras de galinha (Marchiori et al., 2002a).

Spalangia nigra Latrielle (Hymenoptera: Pteromalidae) e Spalangia nigroaenea Curtis (Hymenoptera: Pteromalidae) foram espécies que apresentaram maiores porcentagens de parasitismo com 5,3\%. No Brasil, $S$. nigroaenea e S.nigra foram coletadas nos estados de Mato Grosso, São Paulo, Minas Gerais e Goiás, em Musca domestica L. e Stomoxys calcitrans (L.) (Diptera: Muscidae) (Silveira et al., 1989; Marchiori, 2006). S. nigra é descrita como espécie originalmente da região Holártica com ampla distribuição nos Estados Unidos da América e Canadá (Boucek, 1963; Legner et al., 1976). Provavelmente, devido às variações na qualidade e disponibilidade de recursos alimentares ou pelas densidades dos hospedeiros.

A preferência dos parasitóides pelos seus hospedeiros é apresentada na Tab. 1.

Tabela 1. Microimenópteros parasitóides coletados em fezes de búfalos no Sul de Goiás, no período de maio de 2003 a junho de 2004

\begin{tabular}{|c|c|c|c|c|}
\hline Espécie de díptero & $\begin{array}{l}\text { Número } \\
\text { de pupas }\end{array}$ & Parasitóide & $\begin{array}{c}\text { Número de } \\
\text { indivíduos e pupas } \\
\text { parasitadas }\end{array}$ & $\begin{array}{c}\text { Porcentagem de } \\
\text { parasitismo de cada } \\
\text { espécie de parasitóide }\end{array}$ \\
\hline \multirow[t]{3}{*}{ Archisepsis scabra } & \multirow[t]{3}{*}{310} & Paraganaspis egeria* & 4 & 1,3 \\
\hline & & Spalangia drosophilae & 1 & 0,3 \\
\hline & & Trichopria sp.* & 1 & 0,3 \\
\hline \multirow[t]{2}{*}{ Brontaea quadristigma } & \multirow[t]{2}{*}{138} & Paraganaspis egeria* & 1 & 0,7 \\
\hline & & Spalangia drosophilae* & 2 & 1,5 \\
\hline \multirow[t]{2}{*}{ Brontaea debilis } & \multirow[t]{2}{*}{127} & Spalangia cameroni* ${ }^{*}$ & 2 & 1,6 \\
\hline & & Spalangia nigroaenea* & 1 & 0,8 \\
\hline \multirow[t]{2}{*}{ Cyrtoneurina pararescita } & \multirow[t]{2}{*}{19} & Spalangia nigra & 1 & 5,3 \\
\hline & & Spalangia nigroaenea* & 1 & 5,3 \\
\hline \multirow[t]{8}{*}{ Palaeosepsis spp. } & \multirow[t]{8}{*}{1948} & Kleidotoma nigra* & 6 & 0,3 \\
\hline & & Paraganaspis egeria* & 12 & 0,6 \\
\hline & & Spalangia cameroni & 4 & 0,2 \\
\hline & & Spalangia drosophilae & 1 & 0,1 \\
\hline & & Spalangia nigra & 16 & 0,8 \\
\hline & & Trichopria sp. & 9 & 0,5 \\
\hline & & Triplasta atrocoxalis* & 19 & 1,0 \\
\hline & & Triplasta coxalis* & 8 & 0,4 \\
\hline \multirow[t]{6}{*}{ Sarcophagula occidua } & \multirow[t]{6}{*}{931} & Paraganaspis egeria* & 11 & 1,2 \\
\hline & & Spalangia cameroni* ${ }^{*}$ & 8 & 0,9 \\
\hline & & Spalangia drosophilae* & 33 & 3,5 \\
\hline & & Spalangia endius* & 4 & 0,4 \\
\hline & & Spalangia nigroaenea* & 11 & 1,2 \\
\hline & & Trichopria sp.* & 16 & 1,7 \\
\hline Total de pupas: & 3473 & - & 172 & - \\
\hline
\end{tabular}

$* \chi^{2}=146,12 ; \mathrm{P}<0,05 ; \mathrm{GL}=45$ 
Como o uso de inseticidas utilizado no controle de moscas pode causar danos ao meio ambiente e também à saúde humana, a busca de inimigos naturais eficazes pode ser uma alternativa viável para futuros programas de controle biológico. Este trabalho pretende contribuir com conhecimentos da biologia dos parasitóides de dípteros no Brasil.

Palavras-chave: Diptera, Hymenoptera, microimenópteros, fezes de búfalos

\begin{abstract}
The species of microhimenopterous in pupae of Diptera present in buffalo dung, collected in the municipality of Itumbiara, GO, from May 2003 to June 2004 were determined. The dipterous pupae were obtained by the flotation method. They were individually placed in gelatin capsules until the emergence of the dipterous and/or their parasitoids. The overall percentage of parasitism was $5.0 \%$. The more frequent species were: Spalangia drosophilae Ashmead (Hymenoptera: Pteromalidae) with 21.5\% and Paraganaspis egeria Díaz \& Gallardo (Hymenoptera: Figitidae) with 16.3\%.
\end{abstract}

Keywords: Diptera, Hymenoptera, microhimenopterous, buffalo dung

\section{REFERÊNCIAS BIBLIOGRÁFICAS}

AMARAL, M.M.G. Dípteros simbovinos: colonização e sucessão em placas isoladas de fezes bovinas. 1996. 66f. Dissertação (Mestrado) - Universidade Estadual de Campinas, Campinas, SP.

BERTI FILHO, E.; THOMAZINI, M.J.; COSTA, V.A. Artrópodes benéficos associados ao esterco de galinhas poedeiras no Brasil. Rev. Agric., v.71, p.273-286, 1996.

BOUCEK, Z. A taxonomic study in Spalangia Latr. (Hymenoptera: Chalcidoidea). Acta Entomol. Mus. Nat. Pragae, v.35, p.429-512, 1963.

CARVALHO, C.J.B.; PONT, A.C. A revision of New World Brontaea Kowarz (Diptera, Muscidae). Rev. Bras. Zool., v.14. p.723-749, 1997.

CARVALHO, A.R.; MELLO, R.P.; D'ALMEIDA, J.M. Uma revisão sobre himenópteros parasitóides de moscas sinantrópicas, seus principais hospedeiros e habitats no Brasil. Entomol. Vect., v.10, p.237253,2003

DÍAZ, N.B.; GALLARDO, F.E.; MARCHIORI, C. H. Cynipoidea parasitoids of dung-flies in Brazil. II (Insecta: Hymenoptera). An. Soc. Entomol. Bras., v.29, p.469-474, 2000.

GREENBERG, B. Flies and disease - ecology, classification and biotic association. Philadelphia: Princeton Univertisty, 1971. 856p.
LEGNER, E.E; MOORE, I.; OLTON, G.S. Tabular keys and biological notes to commom parasitoids of synanthropic Diptera breeding in accumulated animal wastes. Entomol. News, v.87, p.113-144, 1976.

MARCHIORI, C.H. Microimenópteros de Musca domestica L. (Diptera: Muscidae) coletados em diferentes substratos em Itumbiara, Goiás. Arq. Bras. Med. Vet. Zootec., v.58, p.447449, 2006.

MARCHIORI, C.H. Microhimenópteros parasitóides de moscas em esterco bovino em Cachoeira Dourada, Goiás, Brasil. Entomol. Vect., v.9, p.365:374, 2002.

MARCHIORI, C.H.; CALDAS, E.R.; DIAS, K.G.S. Parasitóides de Diptera em fezes bovinas em vários tempos de exposição em Itumbiara, Goiás, Brasil. Arq. Inst. Biol., v.69, p.37-42, 2002a.

MARCHIORI, C.H.; LINHARES, A.X. Dípteros muscóides associados a fezes frescas de gado bovino e seus parasitóides. Braz. J. Ecol., v.3, p.26-31, 1999.

MARCHIORI, C.H.; OLIVEIRA, A.T.; LINHARES, A.X. Artrópodes associados a massas fecais bovinas no Sul do Estado de Goiás. Neotrop. Entomol., v.30, p.19-24, 2001.

MARCHIORI, C.H.; PEREIRA, L.A.; SILVA FILHO, O.M. et al. Paraganaspis egeria Díaz, Gallardo \& Wash (Hymenoptera: Figitidae: Eucoilinae) as potential agent in the biocontrol of muscoid dipterous collected in several substracts 


\section{Marchiori et al.}

in Itumbiara, Goiás, Brazil. Arq. Bras. Med. Vet. Zootec., v.54, p.662-664, 2002 b.

McALPINE, J.E.; PETERSON, B.V.; SHEWEELL, G.E. et al. Manual of Neartic Diptera. Canadá: Research Branche Agriculture Canada, 1981. 1332p.

MENDES, J.; LINHARES A.X. Atratividade por iscas, sazonalidade e desenvolvimento ovariano em várias espécies de Muscidae (Diptera). Rev. Bras. Entomol., v.37, p.289-29, 1993.

OLIVEIRA, J.T.M.; OLIVEIRA, B.M.A.; GONÇALVES, A.S. et al. Ocorrência de miĺases humanas na região da Baixada Fluminense,
Estado do Rio de Janeiro, Brasil. Entomol. Vect., v.11, p.85-102, 2004.

RUEDA, L.M.; AXTELL, R.C. Guide to common species of pupal parasites (Hymenoptera: Pteromalidae) of the house fly and other muscoid flies associated with poultry and livestock manure. Tech. Bull., v.278, p.1-88, 1985.

SILVEIRA， G.A.R.; MADEIRA， N.G.; AZEREDO-ESPIN, A.M.L. Levantamento de microhimenóptera parasitóides de dípteros de importância médico-veterinária no Brasil. Mem. Inst. Oswaldo Cruz, v.84, p.505-510, 1989. 